\title{
Household Fuel Choice in Urban Nepal: A Multinomial Logistic Regression Analysis
}

\author{
Bharat Raj Bhatta ${ }^{1}$ Kamal Banskota ${ }^{2}$ and Dhiraj Giri ${ }^{3}$
}

\begin{abstract}
From the last decade of the $20^{\text {th }}$ century, it has become increasing evident that uses of firewood, kerosene, LPG and electricity are the major sources of energy used by household for cooking, heating, lighting and cooling. The study examined the effect of socio-economic factors like income, education, geographical location, ethnicity across three different regions. Two cross section data surveyed by National Living Standard Survey (NLSS) in 1995/96 and in 2010/11 are used to analyze the end-use of energy in urban sector for cooking purpose. The studies found there have been significant changes in energy consumption behavior of urban household in these two time periods. Consumption of kerosene has declined over the period of time. Firewood has still contribution with significant amounts although people prefer LPG for cooking purpose. Result shows that household income plays significant role to switch from traditional and transitional fuel to modern fuel. Similarly, household education, ethnic group, geographical locations, family size has significant impact on fuel choice behavior of household. The result suggests that policies and interventions that raise household income, increase the level of education of household head could help to encourage the adaptation of modern energy source.
\end{abstract}

Keywords: choice of fuel, multinomial logistic regression, modern energy, income, socio-economic.

\section{Introduction}

Energy is a primary input for all economic sector such as household, industrial, agricultural and transportation. Household is one of the most important sectors for energy consumption that accounts one-third of total world energy consumption. Like in other developing countries such as India, Bangladesh, Nigeria, China etc. there has been changes in the energy consumption pattern, traditional to modern fuel, in Nepal along with changes in their economy over the period of time.

Correspondent Author/Email: varaatbhatt@gmail.com

Visiting Faculty, Kathmandu University, School of Arts.

Associate Professor, Kathmandu University, School of Arts. 
According to world energy outlook (2012), Nepal's energy resources are broadly divided into three categories: traditional, commercial and alternatives that shows in figure 1. Traditional energy includes dry firewood, animal dung, and agricultural residues. Fuels with well-established market prices are grouped into commercial fuel and indigenous renewable energy sources are grouped into alternative energy. The share of traditional, commercial and alternative energy resources is $87 \%, 12 \%$ and $1 \%$ respectively. The share of traditional energy decreased from $91 \%$ in $1995 / 1996$ to $87 \%$ in $2008 / 2009$. The annual energy consumption increased by $2.4 \%$, similar to the growth rate of GDP but the growth rate of commercial fuel $(1.6 \%)$ was less than traditional biomass fuel.

However, within the commercial energy system, growth in electricity consumption has been increased by $10 \%$. The annual average growth in consumption of alternative was even more than $15 \%$. Within alternative energy, solar energy consumption has increased by $200 \%$ in annual basis compare to lag year. Increase in the consumption of LPG was also more than $25 \%$, annually replacing kerosene and fire wood and electricity (WECS, 2010). Firewood, coal, kerosene, LPG, electricity, biogas, and solar energy are major energy sources that are available in urban areas. The uses of commercial and alternative sources of energy are more popular in urban areas as these types of energy are easily available in the market and are more easy to use than traditional energy sources. The share of traditional energy sources is less in urban area compare to the share of commercial energy because these fuels are more efficient and easily accessible in the market. In urban sector, about $52 \%$ of total energy consumed by household is used for cooking purpose followed by electric appliance $14 \%$ (washing, cleaning, food preserving), lighting $13 \%$, heating and cooling $10 \%$, animal feeding $8 \%$ and agricultural proceeding $3 \%$.

Energy ladder and Fuel stacking are the two theories that established the relationship between households' fuel choice behavior and their income level as well as other factors that influence to prefer particular energy source. The proposed research tries to reckon energy transition process to estimate energy consumption behavior of the household in urban Nepal using the two NLSS survey data, NLSSI and NLSSIII. The study analyzes three different primary energy sources, firewood, kerosene and LPG. It also identifies different socio-economic factors such as income, household education, geographical location of the house, family size, types of dwelling that is either rented or not, that might explain variation in energy preference.

The study of household fuel choice for cooking in urban Nepal between the period of 1995 to 2011 is of particular importance because during this time Nepal has experienced different socio-economic changes. During this period, sharply 
escalated Maoist insurgency have been destroyed more than fifteen thousand human lives and physical infrastructure worth of at least \$250 million (Mahat, 2003). This civil war changes the social and population dynamic of the country which caused to migration to urban area in search for better security. Increased in number of people migrated abroad for employment opportunities that increase in inflow of remittances from $1.29 \%$ in 1995 to $22.3 \%$ in 2011(CBS, 2011), declined population growth rate from $2.68 \%$ in 1995 to $1.06 \%$ in 2010 (Worldometer, 2017), rapid growth in trade, macroeconomic stability, trade liberalization, privatization, are some of the major positive indicators for improvement of the economy. As a result, the poverty line ranges from $41.8 \%$ in 1996 to $25.16 \%$ in 2011 (CBS, 2005, 2011). Also the aggregate annual GDP grew by $5.3 \%$ per year and PCI by $2.5 \%$ per annum during 1990 to 2001 A.D. All these socio-economic changes may have changed household energy consumption behavior. It is imperative to study changes in such behavior that have significant policy implications.

Analyzing the change in energy consumption pattern is important, as findings of such analysis have vital policy implications. It helps to predict the energy of the urban area so that the government can make investment decisions on production sectors accordingly. Study of energy consumption behavior of households using multinomial regression model was conducted in India, China, Bangladesh, Nigeria and in other developing countries where the people change their primary cooking fuel from traditional to modern fuel types. However, substantial quantitative research studying urban fuel choice behavior for cooking in Nepal is lacking. As Nepal is least developed nation still in political transition, most of the economic studies are tactical, focusing on mitigating immediate crisis stemming from political instability. Therefore, the present research contributes long term strategic goal - contributing in terms of urban energy policies.

This study analyzes the consumption pattern of types of energy sources for cooking in urban households of Nepal. We focused our study in urban areas because comparing to rural areas, urban areas have Accessibility, Affordability and Availability (3A)'s of modern energy to satisfy residents' energy needs. We follow exactly the same way of demarcating urban areas and rural areas i.e. all municipalities are urban and all VDCs are rural areas. This study will contribute to identify the socio-economic factors that are associated with energy choice

The rest of the paper is structured as follow: section 2 includes Literature reviews of different other researches that are similar to this study conducted in different part of the world. Energy transition theory is also explained in this section. Section 3 is methodologies section which includes data, description and model estimation 
to support energy theory. Section IV describes descriptive status of variables, results and discussion. Finally, section VI concludes the study.

\section{The Literature Review}

Literature review consist different studies that are similar to this study which tried to investigate factors affecting fuel choice in household of developing countries. It does not include the review of studies that are conducted in developed countries because the energy consumption pattern of such countries is different than energy consumption pattern of household in developing countries. Studies in developing countries focus on the effect of demographic characteristics, income and price on fuel. Following paragraphs present the brief review of previous studies focusing on household fuel choice and switching strategies and highlight existing knowledge gap.

The study of Farsi, Filippini and Pachauri (2007) analyze cooking fuel consumption pattern in urban households of India. It assumes that Primary fuel sources for cooking are fire wood, kerosene and LPG only. The study chooses cooking fuel because the bulk of the energy used in household even today is for cooking. The choice of energy share by primary fuels for cooking is dependent variable of the model and price of the fuel, household monthly income, household monthly expenditure per person, age of the household head, number of person in household, household head with single member, household with female head, household income from casual labor, education of household head which are further sub divided into illiterate, primary school and university education, residence in metropolitan area.

The finding of the study shows that price of the LPG and price of kerosene are significant and has negative impact so that the increase in the price results shift away from particular fuel towards other fuel.

The study by Zhang and Hassen (2014), who use the probit model for household fuel choice for cooking, shows that there is substitution effect on price of coal, Liquefied Natural Gas (LNG) and firewood. When the price of LNG increases, the probability of choosing coal for primary fuel for cooking also increases. The study of (Alem, Beyene, Kohlin, \& Mekonnen, 2013) conducted in urban Ethiopia shows similar results that fuel prices are important determinant for fuel choice. With the increase in income and the increase in the price of fuel wood, household tend to shift to clean fuel source. Firewood is assumed as inferior goods; kerosene and LPG are supposed to normal goods. Therefore, as change in price of firewood tend to shift towards normal goods. 
In the study done by Babanyara et al. (2010) shows that the main cause for consumption of fuel wood as primary energy source to meet their energy need is due to the fact that other sources of energy are experiencing hike in price. The effect of increase in price of other energy source shows increasing the number household that depends on fire wood as main source of energy. Thai Government gives electricity subsidy to urban poor, and lowers the monthly service charge to encourage poor household to consume electricity (Shrestha, Kumar, Martin, \& Dhakal, 2008).

Household Income has significant positive effect showing that increase in income leads to increasing the probability of choosing LPG as a cooking fuel over firewood and kerosene (Farsi, Filippini, \& Pachauri, 2007). As income increases the household substitute more and cleaner fuel sources. This shows positive relationship between income and choice of fuel. In the study of China by using probit model income is shown to a significant role in determining household choice of fuel for cooking in urban China. As the income increases, household prefer LNG as primary fuel for cooking but the probability of choosing fuel wood and coal as primary fuel for cooking has decreased (Zhang \& Hassen, 2014). Also shows the positive relation between income and energy consumption, a different approach of increasing income in energy consumption. There is positive relationship between income and household demand for commercial fuel (Nazer, 2016).

But different case was found in the study by Ado et al (2016) at Buchi Metropolis. The finding shows as income increases, households tend to adopt modern fuel but not perfectly substituting traditional fuel with modern or transitional fuels. Nigeria faced fuel stacking behavior as income increases rather than energy ladder hypothesis. Similarly, in the study of household fuel choice in Ethiopia by using multinomial logit analysis shows that income plays a significant role for fuel choice. As income increases, the household increase the number of fuel type used by household (Alem, Beyene, Kohlin, \& Mekonnen, 2013). Another study on Myanmar shows major cities are electrified and as income increases the consumption of modern electric appliances increases ( Kyu \& Sajjakulnukit, 2014).

In Nigeria there is negative correlation between income and consumption of biomass (Saad \& Bugaje, 2016). If the income of household increases, the households try to substitute biomass fuel by modern fuels. Study conducted in case study of Dhulikhel of Nepal by using Pearson's coefficient results shows there is positive relationship between energy consumption and income of the household (Shrestha, Ghimire, Phuyal, \& Khanal, 2016).

The size of the household is another demographic variable that determines the fuel choice of household. With the increase in household size there is increase in the 
probability of consuming LPG. There is positive relationship between household size and probability of choosing LPG (Farsi, Filippini, \& Pachauri, 2007). The increase in size of household which may increase the volume cooked and it requires more energy to cook food is found in the study of rural area of Nigeria (Oyekale et al., 2012). Ouedraogo (2006) suggests that, in urban Burkina Faso, households with fewer members are twenty-sixth times more likely to adopt LPG and less likely to use firewood for cooking.

Consistent with the finding of Ouedraogo (2006) larger household size is associated with a higher probability of choosing firewood as the primary cooking fuel and a lower probability of choosing LNG (Zhang \& Hassen, 2014; Ado et al., 2016; Nazer, 2016; Kanangire et al., 2016). Pearson's coefficient result shows that there is positive relationship between household size with total energy consumption and also the cost of energy in the study of Dhulikhel municipality of Kavreplanchowk districts of Nepal by (Shrestha , Ghimire, Phuyal, \& Khanal, 2016).

Another important variable for fuel choice in household sector is head of household. Energy consumption pattern of household with female head is different than the consumption pattern of male heading household. Female headed household have a positive effect on choosing LPG (Farsi, Filippini, \& Pachauri, 2007). In another study of India had similar result that female-headed households were having more chances to choose either solid fuel only or a mix of solid and non-solid fuels as their main fuel (Patil \& chattopadhaya, 2010). Compared to the male household, the decision maker in female headed households understand better the health risk and inconveniences of cooking with unclean fuel sources therefore female headed households are less likely to choose firewood or coal as their primary cooking fuel, and more likely to choose clean fuel (Zhang \& Hassen, 2014). The study of (Kanangire, Mbabazize, \& Shukla, 2016) shows that more women household heads had embraced the improved biomass stove technology than men due to its effectiveness in conserving the fuel.

However, the study, conducted in urban Zambia by (Tembo, Mulenga, \& Sitko, 2015), shows different results. This study did not support the results of (Farsi et al) as the size of the household and the sex of the head being female have a negative effect on the probability of choosing cleaner fuels. Share of females in the household is negatively and significantly related to the probability of choosing mixed fuels, but has no significant effect on choice of solid fuels (Alem, Beyene, Kohlin, \& Mekonnen, 2013). The study of Nazir (2016) in Indonesia shows that household head man wiser men in frugality in energy consumption and consume less energy compared to household head female. Similar results is found in the study of Adu (2013) in Ghana found that male heads of the family have the 
possible opportunity of using energy cleaner and more efficient than female heads of household, also such is the case with study by Islas (2013) on the energy consumption of households in Mexico.

In addition, fuel selection for cooking in household level is also significantly affected by education. The more household head are educated, the higher probability of choosing clean energy. Educated household are expected to choose more clean energy sources. Sutdies in urban India found that the household head being illiterate or only having primary education increases the probability of choosing firewood or kerosene as a cooking fuel, whereas those households where the head has a higher level of education are more likely to use LPG (Farsi, Filippini, \& Pachauri, 2007). Similarly, the studies by Zhang and Hassen (2014) in China shows educated household select more clean energy source. The study uses dummy variables for education attained by households are categorized into primary school degree, secondary school degree and university degree. Household heads having a primary school degree or higher are more likely to choose higher ranked energy sources than those who do not have a primary degree. More specifically, household heads having a primary degree are only slightly more likely to choose clean energy (LNG) than those with no primary school degree. Research in Bauchi Metropolis in Nigeria also shows similar results in line of Farsi et al (2007) that the education of the household affects the choice of modern fuel. As the level of education increases they are more inclined to adopt modern fuel.

Again, the studies of India by (Patil \& chattopadhaya, 2010) and of Indonesia by (Nazer, 2016) show education of head of the household and type of fuel use are positively associated with each other. Both in rural and urban area, as education of head of the household increases, use of the clean fuel also increases.

Education is strong determinant in fuel choice of Ethiopia shown in the analysis of household fuel choice in urban Ethiopia (Alem, Beyene, Kohlin, \& Mekonnen, 2013). The study found two possible explanations for increase in clean fuel choice with respect to change in education level: one is education increases the opportunity cost of fuel wood collection time. Second, it could help improve awareness about the negative effects of biomass fuels on health. Therefore, education can be long term policy to shift household fuel from traditional to cleaner cooking fuels. Because if people are not educated and lack knowledge on how to use LPG, they fear about it and are also afraid of accidents caused by LPG and electricity is also the problem for energy consumption in rural areas (Francis, 2016).

But the study of Rwanda by (Kanangire, Mbabazize, \& Shukla, 2016) shows different results than previous studies. Education level of the household head did 
not matter when it came to adoption of the technology but the benefits of the device.

In addition, the age of household also has impact on fuel choice by household for cooking. The age of the head of the household have positive effect on the probability of choosing LPG (Farsi, Filippini, \& Pachauri, 2007). Similar results in different studies show that as age of the head of the household increases, household choose higher quality fuel for cooking (Zhang \& Hassen, 2014; Alem et al., 2013; Nazer, 2016).

The major source for traditional energy in Nepal is forest. It has decreased from $39.6 \%$ in 1999 to $37 \%$ in 2005. During the last 10 years 1995-2005 period loss of forest is about $1.24 \%$ (WECS, 2013) . However, the community forest has been one of the priority programs of forestry development. Animal residues are supplied and served as complementary biomass energy sources to compensate the scarcity of fuel wood. It has been the second largest energy source in terms of total primary energy consumption. Agricultural residue is the third largest indigenous energy source according to (WECS, 2013). Hydro electricity, petroleum, natural gas and coal are the major commercial energy use in Nepal. Hydro electricity is the major source for power generation, and has huge potential for generation. Nepal imports all the petroleum products from India or oversea and in handed by government despite the natural gas, which is distributed by private sector under the supervision of government. (NOC , 2017).

Countries like Nepal have potential to produce electricity from locally available renewable sources. Harnessing energy from renewable sources can improve the electricity access in rural area that reduce the over dependence on traditional energy sources as well as foreign imported fuel (Nepal, 2011). Only 18\% of total population lives in urban area and rest of $82 \%$ live in rural area. The rural dominance of the country implies poverty as $38 \%$ of the population has disposable income of $\$ 1.25$ a day and average per capita income is \$427 (WDI , 2011). Country uses three types of energy sources: commercial, traditional and alternative energy. The total energy consumption of country is primarily driven by traditional sources. In 1995 the share of traditional energy in total energy was $91.14 \%$ which marginally declined in 2008 and became 87.1\% (Gurung, Bryceson, \& Oh, 2011). In the same time period, there was slight increment in the consumption of commercial energy and share was raised by $12.2 \%$ in 2008 from $8.75 \%$ in 1995 . The rate of electrification was increased to $43.6 \%$ in 2008 as compared to $30 \%$ in 2005 . Only $34 \%$ of the rural household had access of electricity in rural area as compare to $90 \%$ in urban area. The urban population growth rate is $18 \%$ while rural population growth was growing at $1.2 \%$ (IEA, 2008). 
So far, studies in fuel wood consumption of urban area for cooking have not been done in country level. There are few researches conducted in district level by collection sample which are designed to fulfill the requirement of study purpose. By using national level data of energy, consumption by household level was not found. However, in some districts, such as in Kathmandu, Bhaktapur, Lalitpur, and Kavreplanchowk, few studies are done. The focuses of these studies are the trend of consumption pattern of energy by household level. Rather than the factor for determining the energy consumption pattern in those studies, they try to show the share of energy consumption for different purpose such as cooking, lighting, heating etc. for example in the study by (Shrestha , Ghimire, Phuyal, \& Khanal, 2016) in of Dhulikhel municipality of Kavreplanchowk districts found that cooking is most intensive end use followed by electrical appliances in urban area and energy use for water heating in rural area. Cooking consumes most energy amounting $75 \%$ of total energy consumption by household, although the proportion on total cost of cooking is lesser than the proportion on energy consumption. Study conducted in three districts of Kathmandu valley also shows that cooking was the most dominated end use which accounts for $69 \%$ of total energy consumption by households (Rajbhandari \& Nakarmi , 2014).

LPG is the main source of fuel for cooking in urban areas while household in rural areas depend mostly on biomass. In the study of Shrestha, Ghimire, Phuyal, \& Khanal (2016) in Dhulikhel, mostly urban territory, the use of LPG for cooking purpose is significant, Kerosene is used as a backup fuel for load shedding. Similar results found in the study of Bhaktaur by (Bajacharya \& Nakarmi, 2014). Most of the households have LPG ( $82.42 \%$ in rural and $99.11 \%$ in urban) for cooking but in rural area household rely on locally available firewood and agricultural dung for cooking and usage of LPG is very less, only for making tea or on the arrival of guests. Rajbhandari \& Nakarmi (2014) found LPG and biomass are the major source of energy for cooking in the study of Kathmandu valley.

The study from different articles in developing countries such as India, China, Nigeria, Ethiopia shows that there is different source of fuel are consumed for cooking purpose. The state of household shifting from traditional fuel to modern fuel is influenced by economic and demographic variables. From the review of different article, I came to the conclusion that in developing countries, there is the trend of choosing multi-fuel rather than energy-ladder theory. Income plays significant role to determine the choice of fuel for cooking in urban households. There are other variables such as education, family size, gender of household, price of fuels, location of houses, occupation of household head, age of the household head, size of house which also determine the choice of fuel for cooking. 
This study use variables such as income of household, highest level of education attained by household head, marital status of household head, economies of scale of family size and location of houses as independent variables. The study uses choice of fuel for cooking as independent variables.

\subsubsection{Energy Ladder and Fuel Stacking Behavior}

In this hypothesis, sources of energy are classified into three groups: traditional, transitional and modern fuel. Traditional fuel sources such as firewood, animal dung etc. are more polluted and less costly (Goldemberg, 2000) and its efficiency is also low, therefore, it is placed in the lower rung of the ladder. Similarly, Transitional fuel for instance: kerosene and coal are placed in this category. These energy sources are more expensive than earlier one and are high efficient and are positioned in middle rung of the ladder. Finally, energy sources for example, LPG, Electricity are lies in this group. This energy group is placed in top position of the rung because these sources are more efficient and expensive than both of the previous energy group located in the lower rung of the ladder.

Household income is the key factor for energy switching behavior of household. There is positive relationship between income and types of fuel prefer by households. As income increases household substitute the traditional less efficient fuel sources by costlier and efficient fuel and vice-versa (Hosire \& Dowd, 1987; Heltberg, 2004).

Although income has positive role to fuel type, there are several other factors that influence the choice of fuel. Educated household head, for example, has prefer more efficient fuel for cooking purpose (Alem et al, 2013; Francis, 2016; Farsi et al., 2007, Patil \& Chattopadhyaya, 2013; Nazer, 2016; Zhing \& Hassen, 2014). Similarly, Price of fuel is another factor for determining its consumption for cooking purpose. Indeed, price is important factor for fuel consumption, but this study assumes price as constant variable. Zhang and Hassen (2014) shows that there is a substitution effect on price of coal, Liquefied Natural Gas (LNG) and firewood in China. Alem et al. (2013) in urban Ethiopia and Babanyara (2010) in Nigeria also treated firewood as an inferior good and modern fuel as a normal good. Socio-demographic variables such as size of family, age of household head, marital status of household head, geographical location, age of household head, and sex of household head also affect the choice of household fuel consumption for cooking by household (Zhang \& Hassen, 2014; Ado et al., 2016; Nazer, 2016; Kanangire et al., 2016; Tembo et al., 2015; Patil \& Chattopadhaya, 2010). 
Therefore, another model for fuel consumption, which seems to be more popular in the country like Nepal, is fuel stacking. Generally, people in poor nations use energy portfolio because of 3A's. They could not rely on any particular source of energy for all of their activities, therefore, they use several fuel types for their daily activities. Household adopts new technologies, may use advance fuel but they adopt it as partially rather than complete substitutions (Elias \& Victor, 2005). Therefore, even if the 3A's of fuel they always use varieties of fuel sources and use energy from traditional and modern sources of fuels.

Figure 1: The Energy Transition Process (Schlag N, 2008)

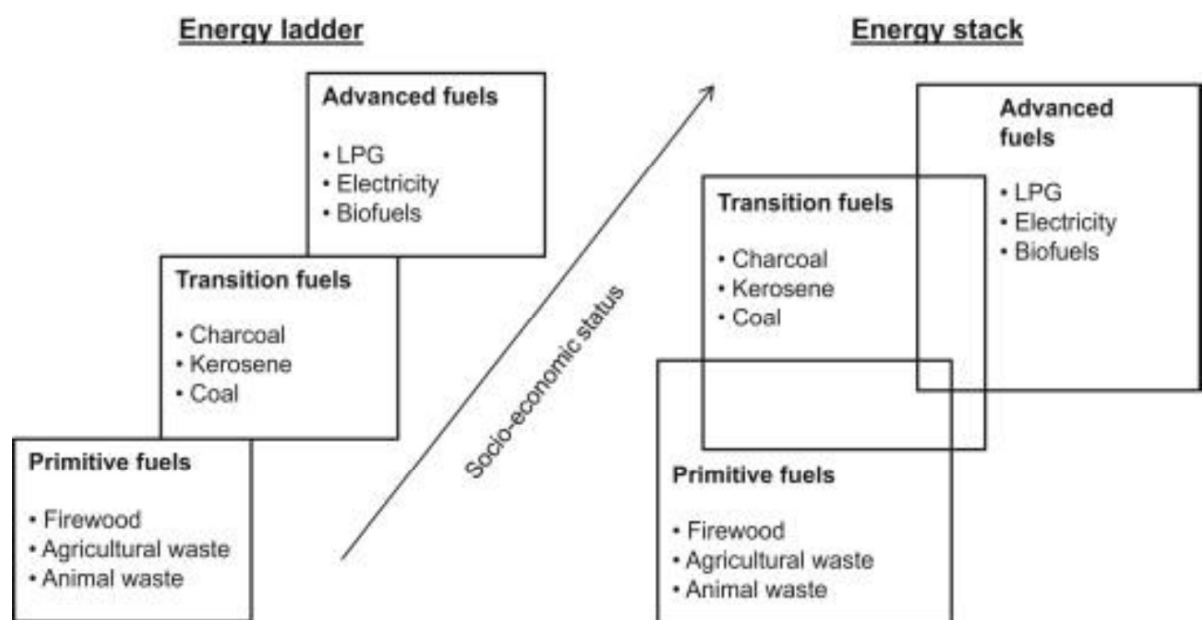

In Uganda, household uses mix fuels mitigate the energy shortage and cost incremental problem. Households in urban areas connected with electricity also, use charcoal as a predominant fuel for cooking. It could be due to high electricity tariff, unreliable electricity supply compelling household to seek out alternatives in order to maintain regular fuel meal, and a large proportion of rural urban migrate may feel comfortable with traditional fuel as source of energy. Socio-cultural factor is also one of the factors for highly reliance on charcoal. The study using multiple regression method shows rather than energy ladder hypothesis; Nigeria faced energy-stacking behavior Ado et al. (2016). The finding also showed that income increases, households tend to adopt modern fuel. However, the adopted modern fuel does not perfectly substitute traditional fuel. Because of frequent power outage, non-availability of LPG and other supply disruptions household in Bauchi Metropolis, Nigeria, use multiple fuels. This study use ordered probit model for analyzing household fuel choices for cooking (Zhang \& Hassen, 2014) also showed the fuel stacking behavior of urban Chinese household for cooking. Similar results 
were found in the study of Alem et al. (2013) where they use multinomial logit model.

\section{The Methodology}

The household level data used in this study are from the Nepal Living Standard Survey (NLSS) conducted by the government of Nepal, Central Bureau of Statistics (CBS) jointly with the World Bank launched the Nepal Living Standards Survey (NLSS). This has become a popular survey, as it carries out studies that are important for the process of decision making. The survey was carried out collecting a comprehensive set of data on the different aspect of household welfare such as demography, consumption, income, housing, labor market, education, health, and other socio-economic factors. NLSS followed the Living Standard Measurement Survey (LSMS) method which is developed and promoted by the researchers of the World Bank. Nepal Living Standard Survey (NLSS) was conducted in three different periods 1995/1996, 2003/2004 and 2010/2011. This study has included the data of 1995/1996, and 2010/2011 as 2003/2004 was the period of peak Maoist insurgency, so the given data might not reflect the actual scenario. Another reason for the usage of data from these two periods is to compare the situation before and after the Maoist insurgency.

In this study multinomial logistic regression model is used to analyze the data. Multiple logistic regression is used when dependent variable has two or more categories. It uses one of the categories as referenced category (any one of them) and compares other categories with reference category. It compares remaining categories with reference category by taking log odds. In general, logistic model $\log$ odds are the log of probability ratio of particular category versus reference category.

The dependent variable of this study is the choices of fuel for cooking in urban households. Rather than amount of energy consumes by household, it explains the types of fuel, firewood, kerosene and LPG, used by household for coking. Independent variables used in this study are: family size of the household includes all the family members living together under a same roof and using same kitchen; highest level of education attained by household head categories : as illiterate, primary education, secondary education, university (or higher) education, total household income, marital status of household head categories into ever married (married, divorced, separated, widow/widower) and never married, geographical location of house categorized into three different geographical locations: mountain, hill and terai, rent part dwelling used to explain whether a family lives in rented house or not.

Multinomial regression model used in this study is shown in equation 1. 


$$
\begin{aligned}
\log \text { odds }=\log & \left(\frac{P((Y=j \mid x)}{P((Y=J \mid x)}\right) \\
& =\beta_{0}+\Sigma \beta_{i} X
\end{aligned}
$$

Where, $X$ is set of independent variables: $\Sigma \beta_{i} X=\beta_{1} \ln y+\beta_{2} F z+\beta 4 E d u+\beta_{5} G l+$ $\beta_{6} M+\beta_{7}$ Rnt

Where,

$\ln y=\log$ base $e$ of total income of household.

$F z=$ Family size of household.

$E d u=$ Highest level of education attained by household head.

$0=$ Illiterate, $1=$ Primary education, $2=$ Secondary education,

3 =University (or higher) education

$G l=$ Geographical location of household .

$0=$ Mountain, $1=$ Hill, $2=$ Terai

$M=$ Martial status of household head.

$0=$ Ever married, $1=$ Never married

$R n t=$ Rent part of dwelling

Yes $=1$ and $\mathrm{No}=2$

$\beta_{1}, \beta_{2} \ldots \ldots \ldots \ldots, \beta_{7}$ are parameter associated with independent variables.

For this model there are two log odds and compare each of them with reference (base) category. It is assumed that log odd is a linear function of the predictor. The log odd ratio shows that how many times more likely particular variable is to be chosen relative to the reference category.

The dependent variables of this study are choice of fuel for cooking: Firewood=1, Kerosene $=2$ and $\mathrm{LPG}=3$. For multinomial regression we have 3-1 $=2$ equations. Each equation model has the odds of choice relative to baseline. We considered firewood as a baseline variable. One is odds of choosing kerosene relative to firewood:

$$
\begin{aligned}
& \log \left(\frac{P(Y=2 \mid x)}{P(Y=1 \mid x)}\right)=\beta_{0}+\Sigma \beta_{i} X \\
& \quad \log \left(\frac{P(Y=3 \mid x)}{P(Y=1 \mid x)}\right)=\beta_{0}+\Sigma \beta_{i} X
\end{aligned}
$$

Equation (2) and (3) shows how the independent variables, X, affect the relative odds of Kerosene among Firewood and LPG among Firewood respectively. In above equation $\beta_{0}$ is an intercept and $\beta i$ is a vector of regression coefficient. The set of coefficient shows us how independent variable affects relative odds of LPG vs. Firewood. 


\section{The Results and Discussion}

\section{Descriptive Statistics}

Distribution of household's main fuel for cooking in two-time period is explained in Figure 2. It shows that during time period 1995-96 a majority of household uses kerosene $(45.4 \%)$ as main fuel followed by firewood (32.9\%) and LPG $(21.7 \%)$. In NLSS-III 2010-11, observations reveal interesting information about household's usage of kerosene. Consumption of kerosene as main fuel for cooking has drastically declined in the year 2010-11. Of the total households included in analysis, kerosene shared only about 2 percent. However, during this period, the household consuming LPG gas was increased that is 59.7 percent of total households use LPG as main fuel for cooking. The rapid change in consumption of kerosene and LPG gas is due to the cost of kerosene being higher than LPG and increase in number of LPG distributors. LPG is more efficient and easy to use than kerosene, therefore, the kerosene users substituted kerosene with LPG gas as their main fuel for cooking. The per capita income of people rose in this time period and almost all household uses kerosene in previous are shift to LPG because of similar cost of these two sources. Nevertheless, those, who are unable to afford LPG and kerosene, stick with firewood as main fuel source.

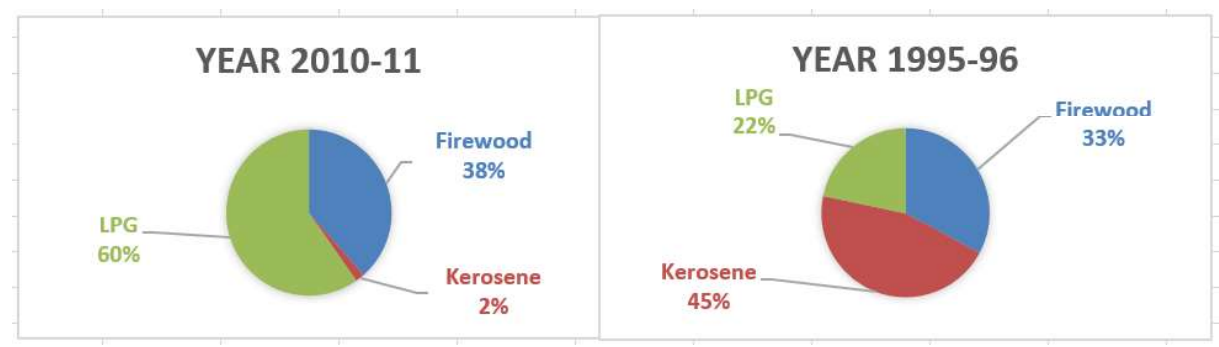

Figure 2: Distribution of Cooking Fuel Choice in the year (1995-95) and year (2010-11)

Table 1 depicts the descriptive statistics of the demographic variables and economic variables that affect the choice of fuel for cooking in urban areas. Variables such as geographical location of household, highest level of education attained by household head, marital status of the household head and rent part of dwelling are categorized in different categories.

On the geographical basis, Nepal can be categorized into three different regions: terai, hill and mountain but we categorized the location into Hill and Terai region because mountain region does not have any urban areas. Of the total households included for this study, 85.6\% household lived in urban hill area whereas in 2010- 
2011 this figure decreased to $62.4 \%$. It could be due to migration of people from hilly region to terai region of the country. Because of this reason the study only compares terai and hill region for analysis. There is no urban area in mountain region therefore it has zero data in the following table. There is an improvement in the higher level of education up to 18.5\% in 2010-11 compare to 1995-95, which was only $11.4 \%$, as indicated by declined in illiterate household head in 2010-11 from 41.5 to $30.8 \%$ in $1995-96$.

Table 1: Descriptive Statistics (1995-96 \& 2010-11)

\begin{tabular}{|c|c|c|c|c|}
\hline \multirow[t]{2}{*}{ Variables } & \multicolumn{2}{|c|}{ Year 1995-96 } & \multicolumn{2}{|c|}{ Year 2010-11 } \\
\hline & Total & Percentage & Total & Percentage \\
\hline Geographical Location & 465 & & 1186 & \\
\hline Mountain $=0$ & 0 & 0 & 0 & 0 \\
\hline Hill $=1$ & 398 & 85.6 & 740 & 62.4 \\
\hline Terai=2(Reference category) & 67 & 14.4 & 446 & 37.6 \\
\hline Education of Household head & 465 & & 1186 & \\
\hline Illiterate $=0$ (Reference category $)$ & 193 & 41.5 & 365 & 30.8 \\
\hline Primary education $=1$ & 75 & 16.1 & 199 & 16.8 \\
\hline Secondary education $=2$ & 144 & 31.0 & 402 & 33.9 \\
\hline Higher education $=3$ & 53 & 11.4 & 220 & 18.5 \\
\hline Marital Status & 465 & & 1186 & \\
\hline Ever-Married $=0$ & 449 & 96.6 & 1132 & 95.4 \\
\hline Never-Married $=1($ Reference category $)$ & 16 & 3.4 & 54 & 4.6 \\
\hline Rent Part of Dwelling & 465 & & 1186 & \\
\hline Yes $=1$ & 154 & 33.1 & 349 & 29.4 \\
\hline No $=2$ (Reference category) & 311 & 66.9 & 837 & 70.6 \\
\hline
\end{tabular}

Average household size was found to be 5.29 members in 1995-96 with the standard deviation of 2.55 whereas in 2010-11 the average size of household is found to be 4.73 family members with standard deviation 2.25 . Similarly, the average income of the households rose from Rs. 1,18,124/- in 1995-96 to Rs.5,20,941/- in 2010-11 indicating increase in the income level of the household. Rs. 45,00,000/- debt was the lowest income recorded at the year 1995-96. Minimum income record was Rs. 57,22,600/- debt and maximum income was Rs. $8,26,32,952 /$ - recorded in 2010-11.

\section{Regression Results}

The results consider overall test of relationship at first. Secondly, strength of MLR relationship was tested to establish strength of MLR relationship and lastly, evaluating the usefulness. 


\section{Overall Test of Relationship}

Multinomial Logistic Regression (MLR) describes the overall relationship between dependent and independent variables. Model fitting information in Table 2 describes the relationship between dependent variable and independent variables. The null hypothesis of the model assumes final model will not have any independent variables in model, alternative hypothesis of the model is final model will have any independent variables in model.

Table 2: Model Fitting Information

\begin{tabular}{clcccc}
\hline Year & Model & \multicolumn{3}{c}{ Model Fitting Criteria } & \multicolumn{2}{c}{ Likelihood Ratio Tests } \\
\cline { 3 - 6 } & & -2 Log Likelihood & $\begin{array}{c}\text { Chi- } \\
\text { Square }\end{array}$ & df & Sig. \\
\hline \multirow{2}{*}{$2095-96$} & Intercept Only & 979.270 & & & \\
& Final & 765.329 & 213.941 & 18 & 0.000 \\
& Intercept Only & 1766.030 & & & \\
& Final & 1402.308 & 363.722 & 18 & 0.000 \\
\hline
\end{tabular}

\section{Strength of Multinomial Logistic Regression Relationship}

Table 3 depicts, Nagelkerke's R square value in two different periods. In 1995-96 it is 0.420 , suggesting that 42 percent variation in dependent variable has been explained by independent variables. Similarly, in 2010-11 Nagelkerke's R square value is 0.341 , suggesting that 34.1 percent of variability is explained by these variables used in the model. The strength of Multinomial logistic regression model was stronger in 1995-96, compared to 2010-11.

Table 3: Pseudo R-square

\begin{tabular}{lcc}
\hline & $1995-96$ & $2010-11$ \\
\hline Cox and Snell & 0.369 & 0.264 \\
Nagelkerke & 0.420 & 0.341 \\
McFadden & 0.218 & 0.205 \\
\hline
\end{tabular}

\section{Evaluating Utility of Logistic Models}

Classification of the table shows the percentage of correctly made prediction of the model based on the explanatory (table 4). In the year 1995-96, the model classifying the overall predictive accuracy rate of the present model is $63.9 \%$. The overall predictive accuracy rate of the present model is $73.0 \%$ in the year $2010-11$. 
Table 4:Prediction Accuracy

\begin{tabular}{lcccccccc}
\hline Observed & \multicolumn{3}{c}{ Predicted 1995-96 } & \multicolumn{3}{c}{ Predicted 2010-11 } \\
\cline { 2 - 8 } & Firewood & Kerosene & LPG & $\begin{array}{l}\text { Percent } \\
\text { Correct }\end{array}$ & Firewood & Kerosene & LPG & $\begin{array}{r}\text { Percent } \\
\text { Correct }\end{array}$ \\
\hline Firewood & 96 & 51 & 6 & $62.7 \%$ & 277 & 0 & 180 & $60.6 \%$ \\
Kerosene & 41 & 158 & 12 & $74.9 \%$ & 6 & 0 & 15 & $0.0 \%$ \\
LPG & 6 & 52 & 43 & $42.6 \%$ & 119 & 0 & 589 & $83.2 \%$ \\
Overall & $30.8 \%$ & $56.1 \%$ & $13.1 \%$ & $63.9 \%$ & $33.9 \%$ & $0.0 \%$ & $66.1 \%$ & $73.0 \%$ \\
Percentage & & & & & & & & \\
\hline
\end{tabular}

\section{Relationship of Dependent and Independent Variables}

Two types of tests are used to identify the impacts of individual independent variables on dependent variables. The Likelihood ratio test shows the overall relationship between dependent variables and independent variables. And the Wald test evaluates whether or not the independent variable is statistically significant.

Table 5: Likelihood Ratio Tests

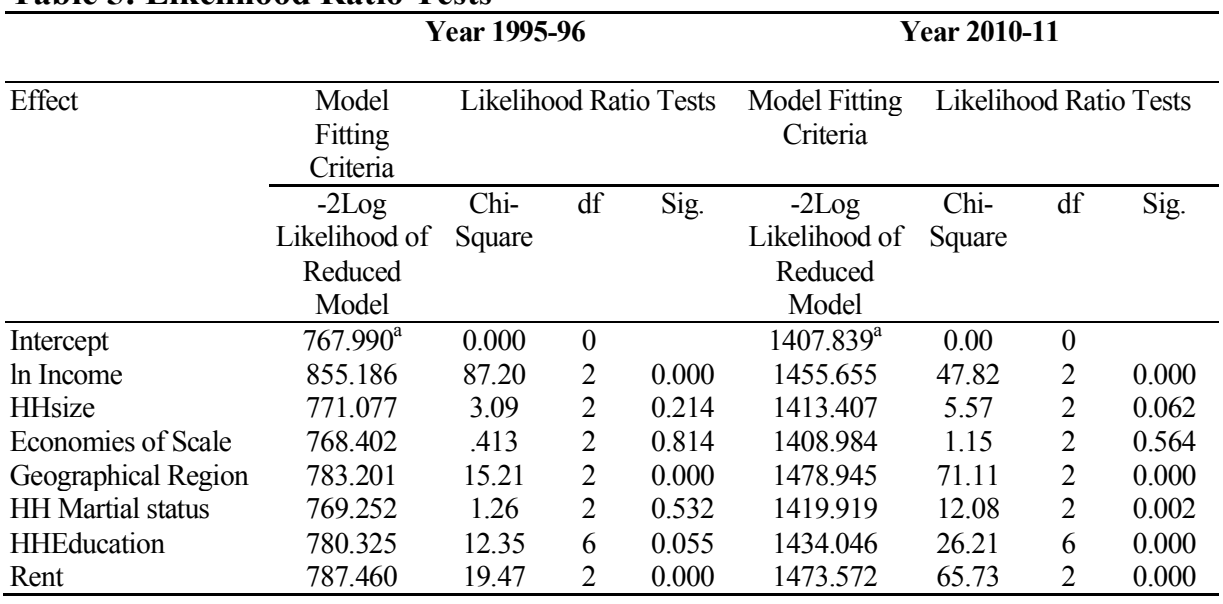

The chi-square statistic is the difference in -2 log-likelihoods between the final model and a reduced model. The reduced model is formed by omitting an effect from the final model. The null hypothesis is that all parameters of that effect are 0 .

a. This reduced model is equivalent to the final model because omitting the effect does not increase the degrees of freedom.

Likelihood ratio shows the contribution of each variable to a model. Referring to Table 5, we can say that in 1995-96 independent variables like income, geographical location, highest level of education by household head and rent part dwelling are significantly and positively associated with dependent variable. 
Similarly, in 2010-11 independent variables like income, education level of household head, marital status of household head, geographical location, and rent part of dwelling have statistically significant and positive association with dependent variable.

\section{Parameter Estimations}

The empirical results of parameter estimation of multinomial logistic regression model of household choice for fuel in urban area in two-time period (1995-96 and 2010-11) are shown in Table 6. The results estimate set of coefficient of independent variables and its standard error. Table also includes odd ratios to interpret consumption of LPG and kerosene relative to firewood.

Most of the parameter estimates on the explanatory variables included in the model are significant and have the expected signs. The results of the parameter estimations are summarized into following section: The results reveal that income has significant and positive effects on choice of kerosene among firewood and LPG vs firewood. During the period 1995-96 as total log income of household increases, they are about 2 times more likely to choose kerosene as a primary fuel for cooking compare to firewood; similarly, the choice of LPG is increases by 6.03 times than firewood. This shows that the higher household income results in preference of modern fuels for cooking purpose in urban area. However, in 2011 there is no any significant relation between income and consumption of kerosene and firewood. It has been observed that the log of income plays significant role on choice of LPG. As income increases, household are about 2 times more likely to choose LPG compare to firewood. Many other studies conducted in India, China, Ethiopia in different time showed that increase in income has increased the choice of modern fuel in two cross sectional data (Farsi et al., 2007; Zhang \& Hossen, 2014; Nazer, 2016; Alem et al., 2013). They also showed that the consumption of modern fuel increases as income increases.

Family size has no statistical significant relation with choice of kerosene as main both periods, whereas it has statistically significant with choice of LPG for cooking. In the case of household head having higher level of education, their choice to consume LPG increases 5.07 times than firewood in 1995-1996. Similar phenomenon was observed in 2010-2011, household head having higher level of education compare to illiterate are 2.80 times more likely to choose LPG compare to firewood.

Geographical region is statically significant on choice of fuel for cooking. During the period 1995-1996, household head from hill region prefer kerosene 3.66 times more than firewood and they prefer LPG 3.29 times more than firewood compare to household head reside in terai region. It shows that consumption of modern fuel 
was more in hilly region in 1995-96. Similarly, in 2010-11, households in hilly region compared to terai were preferring kerosene 3.95 times more than firewood. In addition, household in hilly region, reference to terai choose 3.27 times more LPG than firewood for cooking. It has been observed that in comparison to nevermarried household head, ever-married household head are significantly less likely to choose LPG than firewood for cooking purpose.

Rent part dwelling chose 3.32 times more kerosene than firewood compared to dwelling that were not part of rent in 1995-96. The choice of kerosene than firewood is 4.39 times more in rent part dwelling house in 2010-11. Moreover, rented households preferred 3.80 times more LPG than firewood compare to those houses that are not used for rent in 1995-96. Preference of LPG than firewood is 4.01 times more compare to rent part of dwelling, compare to dwelling that are not rented in 2010-11.

Like in other developing countries such as India, Bangladesh, Nigeria, China, there has been changes in the energy consumption pattern in Nepal along with changes in their economy over the period of time. Increase in income level of household in 2010-11 is insignificant for choosing of kerosene strongly support the energy ladder theory that as income increases people want to prefer less of firewood and more of modern fuel. This shows that kerosene is treated as transitory fuels and people with increasing income prefer more LPG and decrease in consumption of kerosene. Meanwhile, the results also show that, in addition to income, there are several other demographic factor which are also important in determining the choice of fuel for cooking in urban Nepalese households. Family size is not statistically significant for fuel choice for cooking. Never-married households preferred LPG in 2010-11 but it does not affect in 1995-96 analysis.

As expected, increase in education level of households chose LPG and kerosene for cooking rather than firewood. As people getting more knowledge, they are more health conscious and efficiency oriented because they are more aware of opportunity cost of traditional fuel. Education of household is statically significant on choice of fuel for cooking among firewood and LPG only. During the period 1995-1996, household head of primary education prefer nearly 0.3 times than firewood. The households, having the education level from secondary to university, prefer LPG than Kerosene by 0.37 times and 0.25 times more. During 2011 education level is only significant with firewood to LPG. In comparison to the illiterate households, having primary education households prefer 0.43 times LPG. Secondary education and university level education households prefer 0.28 times and 0.36 times LPG than Kerosene and they prefer LPG 3.29 times more than firewood compare to household head reside in terai region. 
Rent part dwelling has encouraged household to choose modern fuel for cooking. Economic progress, infrastructure development and other energy consumption policies cause increase in state accessibility. With increase in accessibility, the sources of primary energy for cooking are also increasing that give households an opportunity to choose more preferable energy sources. Therefore, the consumption of firewood and coal for cooking are substituted by kerosene, LPG and electricity. Increasing per capita income increases the share of disposable income on energy consumption so the affordability of the households is also higher which influences the energy consumption pattern of households. Easy availability of LPG at nearby dealer, expansion of electricity line, reduction in the erratic supply of electricity and petroleum product also influences the energy consumption pattern of households.

\section{Conclusion and Recommendations}

This paper provides results of multinomial logistic regression model to choice of fuel for cooking in urban area in two different time period by using data from Nepal Living Standard Survey 1995-96 and 2010-11. The analysis is used to determine the responsiveness of fuel choice to income, socio-demographic characteristics of households, geographical and also of types of houses and its structure.

The descriptive analysis and the econometric results reported in the paper suggests that firewood and kerosene at the two extreme are more likely to be used in 199595. However, in 2010-11 firewood and LPG are used extremely for cooking purpose and choice of kerosene is decreased. Kerosene seems to be intermediate fuel and as income of households' increase, kerosene is preferred less and treated as inferior goods. As a result, people who could afford modern fuel, chose LPG rather than kerosene in 2010-11. Descriptive variables such as income, family size, education, geographical location, rent part of dwelling have important role to determine the choice of fuel for cooking in urban area is supported by this study in both two time periods. Econometric results show that increase in income has increased the choice of modern fuel in two cross sectional data. However, increase in income in 2010-11 is statistically insignificant for choosing of kerosene strongly support the energy ladder theory that as income increases people want to prefer less of firewood and more of modern fuel. This shows that kerosene is treated as transitory fuels and people with increasing income prefer more LPG and decrease in consumption of kerosene. Meanwhile, the results also show that, in addition to income, there are several other demographic factors which are also important in determining the choice of fuel for cooking in urban Nepalese households. Family size is not statistically significant for fuel choice for cooking. Never-married households preferred LPG in 2010-11 but it does not affect in 1995-96 analysis. As 
expected, increase in education level of households chose LPG and kerosene for cooking rather than firewood. Rent part dwelling has encouraged household to choose modern fuel for cooking.

Compared to 1995-96, income of household increase leads to the increase in the affordability of household to prefer LPG. Increase in other development infrastructure like road, LPG depot, for example, leads to the availability of LPG in different parts of urban area that enables household to substitute kerosene by LPG. The rapid increase in the household's dependency on LPG and drastically decrease in the consumption of kerosene due to improvement in 3A's shows the practice of fuel stacking in urban area of Nepal. Although income determines the choice of fuel, there are other variables as well that influence the choice of fuel by households. Education of household head, marital status, and rent part of dwelling also determine the choice of fuel. Price of fuels also play important role for choosing fuel types which are not included in this study. The reason for not including price in this study is that there is no information about price of fuel types in both NLSSI and NLSSIII survey. Moreover, the information on main fuel for cooking has only one option and this does not give the information about either households have alternative sources of energy for cooking. At the end, this study can conclude that increase in consumption of kerosene and LPG is not only due to the increase in income but other socio-demographic variables also influence the choice of households. This shows the fuel stacking behavior in urban household in Nepal.

From the policy point of view, increase in income may encourage household to consume more efficient fuels. In additional, promotion of higher education can be effective way to encourage household to choose more efficient clean energy as main fuel source for cooking. There are needs to develop infrastructure to make easily availability of fuel for every household and provide them incentives for choosing more efficient fuels and try to include marginalized group of people so that they can afford those fuel for cooking. This effort will reduce pressure on the forest and also reduce time for fetching firewood. 


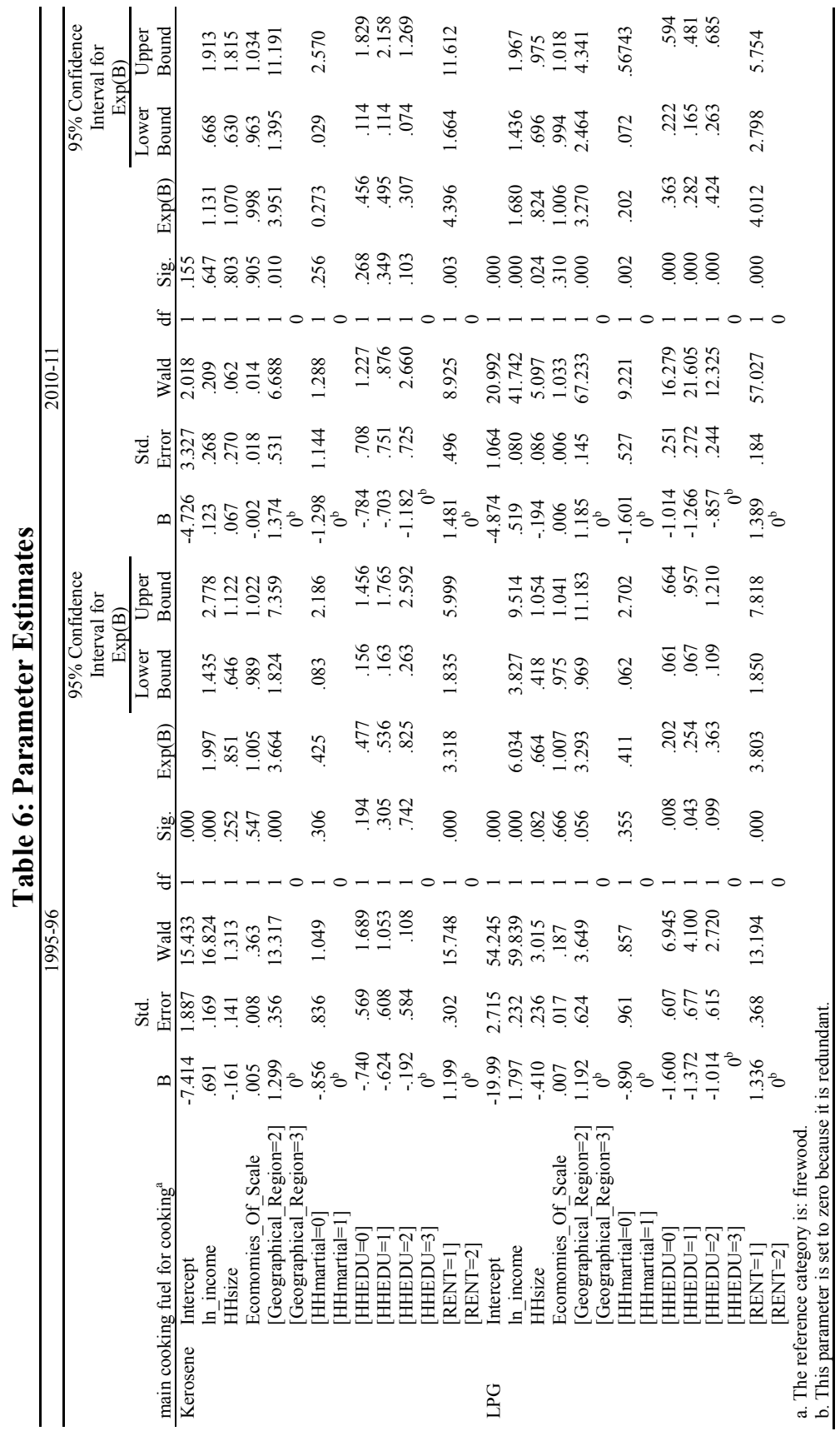




\section{References}

Adepoju, A. O., Oyekale, A. S., \& Aromolaran, O. (2012). Rural households' demand for domestic energy in Odeda Local Government Area (LGA) of Ogun State, Nigeria. Journal of Human Ecology, 40(2), 115-123.

Adhikari, S. R. (n.d.). Poverty dynamics in Nepal between 2004 and 2011: An analysis of hybrid dataset. NRB Economic Review .

Ado, A., \& Darazo, I. R. (2016). Determinants of fuels stacking behaviour among households in Bauchi Metropolis. The Business \& Management Review, 7(3), 84-97.

Alem, Y., Beyene, A., Kohlin, G., \& Mekonnen, A. (2013). Household fuel choice in urban Ethiopia: A random effects multinomial logit analysis. Discussion Paper. Resource for the Future.

Babanyara, Y. Y., \& Saleh, U. F. (2010). Urbanisation and the choice of fuel wood as a source of energy in Nigeria. Journal of Human Ecology, 31(1), 1926.

Bajracharya, Y., \& Nakarmi, A. M. (2014). Current energy consumption in Bhaktapur district. In IOE Graduate Conference (pp. 492-496).

CBS (2005). Poverty trend in Nepal (1995-96 and 2003-04). Kathmandu: Central Bureau of Statistics.

Department of Economic and Social Affairs, Population Division. (2017). Worldometer. Retrieved from http://www.worldometers.info/worldpopulation/nepal-population/

Devkota, S. R. (2005). The politics of poverty alleviation in Nepal: Structural analysis of socioeconomic development from the past five decades. Heidelberg Papers in South Asian and Comparative Politics.

Dhungana, B. R. (2012, December). Remittance and Nepalese economy. p. 7.

Elias, R. J., \& Victor, D. G. (2005). Energy transition in developing countries: a review of two concepts and literature. Program in Energy and Sustainable, Working paper, Standford: Standford University.

Farsi, M., Filippini, M., \& Pachauri, S. (2007). Fuel choices in urban Indian households. Environment and Development Economics, 757-774.

Francis, D. R. (2016). Household energy consumption in rural India. Household Energy Consumption in Rural India, 1(2). 
Goldemberg, J. (2000). World energy assessment: Energy and the challenge of sustainability. United Nation bubns.

Gurung, A., Bryceson, I., \& Oh, S.-E. (2011). Micro-hydro: A promising decentrailized renewable techonology and its impact on rural livelihood. Scientific Research and Essays, 6, 1240-1248.

Heltberg, R. (2004). Fuel switching: Evidence from eight developing countries. Energy economics, 26(5), 869-887.

Hosire, R., \& Dowd, J. (1987). Household fuel choice in Zimbabwe: An emperical test of the energy ladder. Resource and Energy, 9, 347-361.

IEA. (2008). world energy outlook 2011. Paris: OECD/ International Energy Agency.

IIDS. (2012). Nepal Economic Outlook 2011-12. Kathmandu. Institute for Integrated Development Studies.

Kanangire, R. R., Mbabazize, D., \& Shukla, D. (2016). Determinants of adoptation of inproved biomass stove in rural household of Muhazi sector in Rwamagana district. European Journal of Business and Social Sciences, 201223.

Kowsari, R., \& Zerrifi, H. (2011). Three dimensional energy profile: A conceptual framework for assessing household energy use. Energy Policy, 7505-- 7517.

Kyu, W., \& Sajjakulnukit, D. (2014). A study of energy consumption of the household sector in Myanmar. Journal of Natural Sciences Research, 42- 48.

Mahat, P. (2003). The conflict assessment and implication for ADB development assistance in Nepal. Kathmandu.

Maria de Fatima, S. R., Zahran, S., \& Bucini, G. (2010). On the adoption of electricity as a domestic source by Mozambican households. Energy Policy, 38(11), 7235-7249.

Masera, O. R., Saatka, B. D., \& Kammen, D. M. (2000). From linear fuel switching to multiple cooking strategies: A critique and alternative to the energy ladder model. World Development, 28, 2083-2103.

Nazer, M. (2016). Household energy consumption analysis. Proceedings of SOCIOINT 2016 3rd International Conference on Education, Social Sciences and Humanities (pp. 50-61). Istanbul: SOCIOINT. 
Nepal, R. (2011). The roles and potentials of renewable energy in less developed economies. University Library of Munich, Germany .

NOC (2017, May 5). Nepal Oil Corporation Limited. Retrieved from Nepal Oil Corporation Limited: http://www.nepaloil.com.np

Patil, K., \& Chattopadhaya, A. (2010). Household energy use and CO2 Emission: Differential and Determinants in India.

Ra, S., \& Singh, B. (2005). Measuring the economic costs of conflict: The effect of declining development expenditures. Working Paper 2. Asian Development Bank.

Rajbhandari, U. S., \& Nakarmi, A. M. (2014). Energy consumption and scenario analysis of residential sector using optimization model-A case of Kathmandu Valley. In IOE Graduate Conference (pp. 476-483).

Saad, S., \& Bugaje, I. (2016). Biomass consumption in Nigeria: Trends and policy Issues. Journal of Agriculture and Sustainability.

Schlag, N., \& Zuzarte, F. (2008). Market barriers to clean cooking fuels in subSaharan Africa: a review of literature. Stockholm Environment Institute, Stockholm.

Shakya, S. R. (2014). Energy consumption trend in Nepal during 1995/96 to 2010/2011.

Shrestha , A., Ghimire, A., Phuyal, S., \& Khanal, K. (2016). study of current consumption of dhulikel municipality. In Proceedings of the International Symposium on Current Research in Hydraulic Turbines (CRHT VI).

Shrestha, R. M., Kumar, S., Martin, S., \& Dhakal, A. (2008). Modern energy use by the urban poor in Thailand: a study of slum households in two cities. Energy for Sustainable Development, 12(4), 5-13.

Sudhakara, B. (2004). Economic and social dimensions of household energy use: A case study of India. In Ortega, E. \& Ulgiati, S. (editors): Proceedings of IV Biennial International Workshop "Advances in Energy Studies". Unicamp, Campinas, SP, Brazil, pp. 469-477

Tembo, S. T., Mulenga, B. P., \& Sitko, N. (2015). Cooking fuel choice in urban Zambia: Implications on forest cover. Michigan State University, Department of Agricultural, Food, and Resource Economics.

WDI (2011). World development indicator. Washinton DC: The World Bank . 
WECS (2010). Energy sector synopsis report. Kathmandu : Water and Energy Commission Secretariat.

WECS (2013). Nepal's energy sector vision 2050 A.D. Government of Nepal, Water and Energy Commission Secretariat. Kathmandu: WECS.

World Bank (2015). Climbing higher: Toward a middle-income Nepal. World Bank.

Zhang, X.-B., \& Hassen, S. (2014). Household fuel choice in urban China: A random effect generalized probit analysis. Working Paper in Economics (595). University of Gothenburg, Germany. 